Special issue of the 3rd International Conference on Computational and Experimental Science and Engineering (ICCESEN 2016)

\title{
Design of Self Compacting Lightweight Concrete Using Acidic Pumice with Different Powder Materials
}

\author{
N. BOZKURT ${ }^{a, *}$ AND V. TAŞKIN ${ }^{b}$ \\ ${ }^{a}$ Bitlis Eren University, Civil Engineering Department, Bitlis, Turkey \\ ${ }^{b}$ Bitlis Eren University, Graduate School of Natural and Applied Sciences, Bitlis, Turkey
}

\begin{abstract}
This paper reports an experimental study on the design of self-compacting lightweight concrete using acidic pumice with different powder materials. For this aim, nine self-compacting lightweight concretes were designed with inclusion of two different fine aggregates and different powder materials. This way, two groups of concrete were designed. First group was composed of single type of aggregate which is acidic pumice from Bitlis Region with barite powder, fly ash powder and pumice powder inclusion, while the second group was generated with river sand as a fine aggregate and acidic pumice from Bitlis Region, as a coarse aggregate with the same powder addition. In the design process, slump-flow, V-funnel and L-box tests were applied to determine the fresh properties of selfcompacting lightweight concrete. After the design, test of compressive strength, which is one of the most important parameters of concrete, was applied to all self-compacting lightweight concretes in early age. Moreover, ultrasound pulse velocity test was also performed on all concrete series at the same ages.
\end{abstract}

DOI: 10.12693/APhysPolA.132.779

PACS/topics: $62.20 .-\mathrm{x}, 81.70 . \mathrm{Bt}, 89.20 . \mathrm{Kk}$

\section{Introduction}

Concrete is one of the most important and most frequently used construction material in civil engineering industry. Moreover, it a preferable material because it is cheap, easy-workable, and durable. As in every industry branch, some important developments have also occurred in concrete technology.

Invention of chemical admixture for concrete is one of the ground-breaking improvements in concrete technology. Due to the chemical admixtures, scientists and experts can produce special targeted concrete, more workable in fresh state, durable in hardened state, for adverse weather conditions.

In the ancient times, high water/cement ratio was used to improve workability properties of conventional concrete. Unfortunately, this method had led to strength and quality losses. Afterwards, high rate of cement usage was experienced to eliminate that situation. This precaution had also resulted in the increase of the concrete production cost. Improvements of chemical admixture technology, however, allowed to create and produce novel concretes which have good workability, strength and durability [1].

Besides the chemical admixtures, fibre inclusion in to the concrete is also another improvement in concrete technology. This technology can not only increase the tensile strength of concrete under load but also increases impact resistance [2].

On the other hand, mineralogical powders or industrial wastes are also evaluated as concrete additives.

*corresponding author; e-mail: nbozkurt@beu.edu.tr
Sarıyer et al. [3] investigated neutron shielding properties of concrete and suggested the usability of ferro-boron in concrete in a form of particle alloy. Özavcı and Çetin [4] emphasized that with the growing population, the amount of waste also increases. For this reason, they worked on the evaluation of waste recycling. They have successfully determined radiation attenuation coefficients of concretes containing different wastes.

However, the most important development in concrete technology is the invention of the self-compactingconcrete (SCC) with chemicals, in the late 1980s. The first official statement on SCC was presented by Ozawa at East Asia-Pacific Conference on Structural Engineering and Construction. Same declaration was given at CANMET/ACI International Conference in İstanbul in 1992 and gained acceleration the spreading of SCC concept all over the world.

The researches on SCC followed in 1994 ACI workshop in Bangkok and in 1996 ACI Autumnal Congress in New Orleans. As a result, SCC has become the focus of attention and interest of the researchers and engineers until these days [5]. It is said that SCC, in the concrete technology, is the most important development observed in recent years. SCC is very effective for passing between the tight re-bars and fill in the complex construction moulds, without vibration workmanship in the fresh state. It also shows high strength and durability properties in hardened concrete state. These fresh and hardened properties lead to improvement in eco-friendly production and, in production quality and speed [6].

Lightness is another property, as important as strength and durability, in regard of earthquakes and similar disasters. Based on TS EN 206 [7], lightweight concrete (LWC) is a special kind of concrete, having unit weight between $800-2000 \mathrm{~kg} / \mathrm{m}^{3}$. One of the preventive protections against the earthquakes is decreasing the death-load 
of the buildings, due to the lightness advantage of this concrete. Therefore, LWCs have been used in structural elements for fifty years and their usage is becoming more widespread day by day.

In addition, LWC can provide energy saving because of its natural insulating character [8]. In designing of this concrete, lightweight aggregates are generally preferred. This way, the death-load of the buildings may be decreased by $20-25 \%$. This reduction leads to structural members having smaller cross-sectional area and design larger mid-span. Furthermore, earthquake behaviour of buildings is also affected positively $[9,10]$.

On the other hand, workability problems and low strength properties are the most important disadvantages of LWC. The number of researches on usability of volcanic pumice in LWC production, as aggregate, has been gradually increasing [11]. Based on TS 3234, Turkish Standard about pumice concrete, volcanic pumice is described as a material having disconnected pores, cancellous perspective, silicate-structure, $1 \mathrm{gr} / \mathrm{cm}^{3}$ unit weight, 6 mohs-hardness and glassy texture [12].

According to the data obtained from Turkish Statistical Institute [13], $40 \%$ of 18 billion $\mathrm{m}^{3}$ of world pumice reserve is located in Turkey. Approximately 50\% of Turkey's volcanic pumice reserve is located in BitlisVan region. Although volcanic pumice has many positive advantages, like lightness and insulation, it causes an increase of water absorption of concrete because of its pores [11].

In this study, the positive properties of two different special concretes, SCC and LWC, have been compounded, eliminating each other's negative properties, and a new special concrete, called self-compacting lightweight concrete (SCLWC), was produced using acidic volcanic pumice from Bitlis region. As a result, this novel concrete shows engineering properties of wider application.

\section{Materials and methods}

CEM I $42.5 \mathrm{~N}$ type cement, which was used as a binder in the study, was provided from Elazı $\breve{g}$ in Turkey. Its specific gravity was 3.11 and it was used at two different dosages $\left(350\right.$ and $400 \mathrm{~kg} / \mathrm{m}^{3}$ ), with the powders. In the designing of SCC, three type of powders were included into the mixes. These powders were barite powder (BP), fly ash powder (FAP) and pumice powder (PP) obtained from Muş, Sivas and Bitlis provinces, respectively. Some specific chemical and physical properties of the powders are presented in Table I. The powders were included into the mixes in two dosages ( 150 and $200 \mathrm{~kg} / \mathrm{m}^{3}$ ) to be able to obtain sustainable mix design with the cement. Total amount of dust material (cement+powder) of all designed mixes was kept constant at $550 \mathrm{~kg} / \mathrm{m}^{3}$.

Natural river sand and fine pumice were used as fine aggregate in the design, while pumice aggregate was used as coarse aggregate. Natural river sand and all volcanic pumice were obtained from Bitlis Region in Turkey. Volcanic pumice of Bitlis region has acidic character and it is a soft material, having specific gravity between 0.69 and $0.95 \mathrm{~kg} / \mathrm{dm}^{3}$. Water and hyper-plasticiser (HP) were kept constant to observe the other material's effect on fresh properties. Mix proportions of all designed SCLWCs are presented in Table II.

TABLE I

Chemical and some physical properties of used powder materials.

\begin{tabular}{c|c|c|c|c|c|c|c|c|c|c|c}
\hline \hline & $\begin{array}{c}\text { Spec. grav. } \\
{\left[\mathrm{g} / \mathrm{cm}^{3}\right]}\end{array}$ & $\mathrm{BaSO}_{4}$ & $\mathrm{SiO}_{2}$ & $\mathrm{Al}_{2} \mathrm{O}_{3}$ & $\mathrm{Fe}_{2} \mathrm{O}_{3}$ & $\mathrm{CaO}$ & $\mathrm{MgO}$ & $\mathrm{SrO}$ & $\mathrm{Na}_{2} \mathrm{O}$ & Others & $\begin{array}{c}\text { Los. } \\
\text { in ign. }\end{array}$ \\
\hline $\mathrm{BP}$ & 4.20 & 94.12 & 2.23 & 0.30 & 0.13 & 0.04 & 0.15 & 2.61 & - & 0.3 & 0.14 \\
$\mathrm{FAP}$ & 2.26 & - & 38.26 & 16.42 & 5.13 & 27.36 & 1.56 & 4.43 & 0.62 & 5.45 & 0.76 \\
$\mathrm{PP}$ & 2.35 & - & 68.08 & 13.12 & 4.47 & 0.71 & 0.14 & - & 5.25 & 6.42 & 1.84
\end{tabular}

TABLE II

Mix proportions of SCLWCs.

\begin{tabular}{c|c|c|c|c|c|c|c|c|c|c}
\hline \hline & \multicolumn{3}{|c|}{ Used cement, water and powders [\%] } & \multicolumn{3}{c|}{ Used aggr. (N:river sand; P:pumice) [\%] } & HP \\
\cline { 2 - 9 } No & C & BP & FAP & PP & Water & $0-4(\mathrm{~N})$ & $0-4(\mathrm{P})$ & $4-8(\mathrm{P})$ & $8-16(\mathrm{P})$ & {$[\%]$} \\
\hline E1 & 11.15 & 4.76 & 0 & 0 & 16.50 & 39.65 & 0 & 10.58 & 15.86 & 2.0 \\
E2 & 12.74 & 3.57 & 0 & 0 & 16.50 & 39.41 & 0 & 10.51 & 15.77 & 2.0 \\
E3 & 11.15 & 0 & 8.85 & 0 & 16.50 & 37.20 & 0 & 9.92 & 14.88 & 2.0 \\
E4 & 12.74 & 0 & 6.64 & 0 & 16.50 & 37.57 & 0 & 10.02 & 15.03 & 2.0 \\
E5 & 11.15 & 0 & 0 & 8.51 & 16.50 & 37.41 & 0 & 9.95 & 14.93 & 2.0 \\
E6 & 12.74 & 0 & 0 & 6.38 & 16.50 & 37.73 & 0 & 10.06 & 15.09 & 2.0 \\
E7 & 11.15 & 0 & 0 & 8.51 & 16.50 & 0 & 43.88 & 7.36 & 11.16 & 2.0 \\
E8 & 12.74 & 0 & 0 & 6.38 & 16.50 & 0 & 41.84 & 7.98 & 11.98 & 2.0 \\
E9 & 12.74 & 0 & 6.64 & 0 & 16.50 & 0 & 42.10 & 8.21 & 12.31 & 2.0
\end{tabular}


The employed test methods were slump-flow, V-funnel and L-box tests, which are limit criteria tests to create SCC characterised fresh concrete mix. Fresh concrete mixes, providing SCC requirements, were filled into the moulds $\left(150 \times 150 \times 150 \mathrm{~mm}^{3}\right)$ and demoulded after one day. Then, all designed SCLWCs, in 1-day hardened state, were cured to the ages of $3,7,14$ and 28-days in water at $21 \pm 2{ }^{\circ} \mathrm{C}$. After curing period, compressive strength and ultrasonic-pulse vvelocity (UPV) tests were carried out on designed SCLWCs, in hardened state.

\section{Result and discussion}

The fresh properties of all designed SCLWCs are presented in Table III. Clearly, it can be seen that there is an improvement in all fresh properties, when the cement dosage has been increased. If Table III is analysed based on powder inclusion, it is seen that the relatively best fresh properties were obtained in the SCLWCs having $\mathrm{BP}$. Unfortunately, it is observed that the most difficulties of the design process during the laboratory work were experienced when working on designing SCLWCs with included BP.

It was noticed that the adhesiveness and viscosityresistance of $\mathrm{BP}$ were very low. This was causing bleeding problems in designed concretes. Furthermore, the usage of $\mathrm{BP}$ is both, increases the concrete weight and decreases the hydration temperature.

On the other hand, FAP inclusion has shown better characteristics in terms of fresh properties and was followed by PP. The lightest concrete design was obtained in the SCLWC including all aggregates acidic pumice with PP (E8). Though the usage of river sand as fine aggregate brought advantages for fresh properties, it induced increasing fresh unit weights of the designed SCLWCs.

TABLE III

Fresh concrete properties of SCLWCs.

\begin{tabular}{c|c|c|c|c|c|c}
\hline \hline $\begin{array}{c}\text { Concrete } \\
\text { mix. }\end{array}$ & $\begin{array}{c}\text { Slump-flow } \\
\text { diameter } \\
{[\mathrm{mm}]}\end{array}$ & $\begin{array}{c}\text { Slump-flow } \\
\text { time, } T_{500} \\
{[\mathrm{sn}]}\end{array}$ & $\begin{array}{c}\text { V-Funnel } \\
{[\mathrm{sn}]}\end{array}$ & $\begin{array}{c}\text { L-box } \\
(\mathrm{H} 2 / \mathrm{H} 1)\end{array}$ & $\begin{array}{c}\text { Conc. temp. } \\
\text {-lab. temp. } \\
{\left[{ }^{\circ} \mathrm{C}\right]}\end{array}$ & $\begin{array}{c}\text { Fresh conc. } \\
\text { unit weight } \\
{\left[\mathrm{kg} / \mathrm{m}^{3}\right]}\end{array}$ \\
\hline E1 & 700 & 1.92 & 4.90 & 0.81 & 1.9 & 1910 \\
E2 & 800 & 0.75 & 4.21 & 0.85 & 3.4 & 1930 \\
E3 & 790 & 1.2 & 7.39 & 0.99 & 2.9 & 1827 \\
E4 & 630 & 1.23 & 6.32 & 0.87 & 3.5 & 1820 \\
E5 & 625 & 3.10 & 7.81 & 0.80 & 3.8 & 1814 \\
E6 & 705 & 3.02 & 8.34 & 0.93 & 4.4 & 1860 \\
E7 & 620 & 2.85 & 5.26 & 0.81 & 2.1 & 1565 \\
E8 & 700 & 2.65 & 6.24 & 0.83 & 4.8 & 1433 \\
E9 & 785 & 1.08 & 5.65 & 0.84 & 3.8 & 1571
\end{tabular}

Figure 1 shows the interaction plots of fresh concrete properties for all designed concretes. When the interaction graphs in Fig. 1 are examined, it is seen that there is a good relationship between fresh concrete properties.

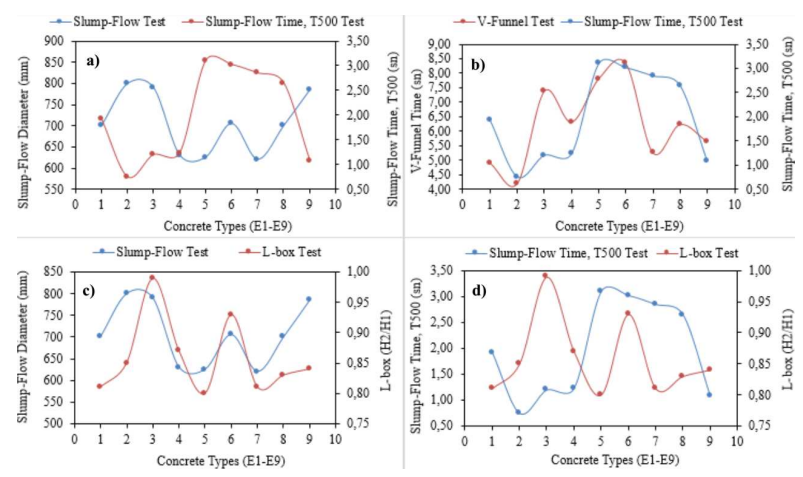

Fig. 1. Interaction graphs of fresh concrete properties for all designed concretes.
Figure 1a shows the flow-diameter, the flow-time interaction graph up to $500 \mathrm{~mm}$ diameter. This graph shows that in fresh concrete designs using FAP, the spreading times to a diameter of $500 \mathrm{~mm}$ are similar and very low. This result indicates that the FAP usage increases the fresh concrete viscosity.

On the other hand, although the specific gravity of $\mathrm{BP}$ is very high, compared to other powders, an improvement has been observed in the flow-time with a decreasing amount of BP. This situation excludes the possibility of better spreading of fresh concrete, designed with heavy materials. It is also understood that the viscosities of fresh concrete mixes using PP are higher than those of the others.

Figure 1b also shows that there is a similar relationship between flow and spread times. According to Fig. 1b, reduction of the amount of heavy powder material in fresh concrete mixes and the usage of powders having high cohesion ability gave the best results. 
Figures $1 \mathrm{c}$ and $\mathrm{d}$ show the interaction plots between the spreading diameter and spreading speed and the ability to pass and fill. According to these graphs, the ability of passing of fresh concrete and filling ability are improved when the diameter of spread is increased in the designed fresh concrete. Similarly, improvement in the ability to fill and pass by increasing the speed of spread is observed.

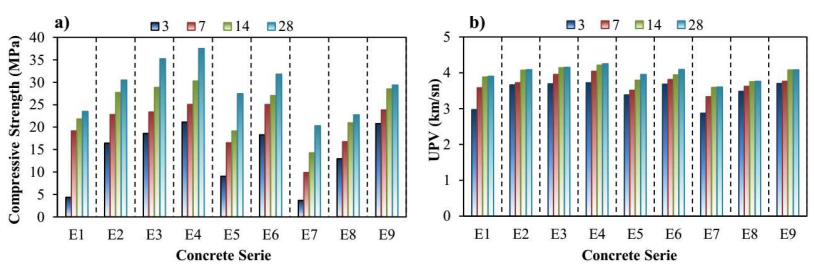

Fig. 2. Hardened state test results: (a) compressive strength test results, (b) UPV test results.

Hardened state test results of SCLWCs are shown in Fig. 2. As an expected result, compressive strength and UPV-values have increased together with increasing curing age. The best results were obtained from the E4 series for all curing days and for both tests.

E4 was including natural river sand and FAP. E7-E9 series were including acidic volcanic pumice aggregate, as fine and coarse fraction. Between these three series the better result was obtained from the E9, having FAP inclusion. It shows that FAP inclusion is resulting in the improvement of hardened state properties of SCLWCs. These results also show that even if sand affects negatively the concrete weight, it is strengthening concrete skeleton. Nearly $40 \mathrm{MPa}$ compressive strength was obtained from the designed E4-SCLWC. Although natural river sand was not used in the designs of E7-E9 series, these series have shown better compressive strength and UPV results than E1, E2, including river sand and BP.

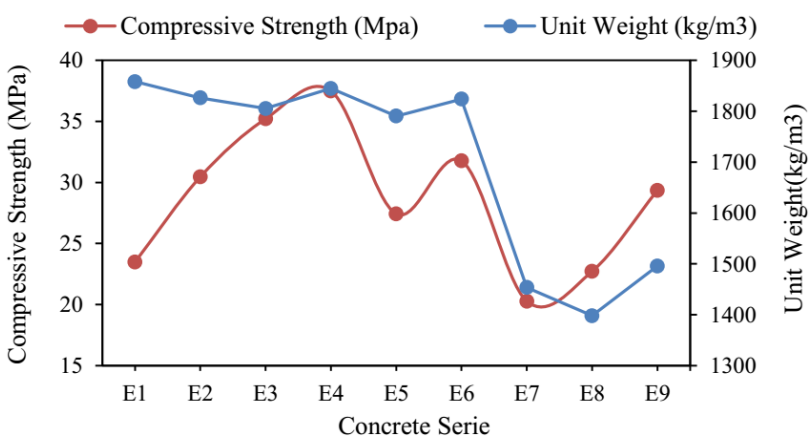

Fig. 3. Interaction graph of compressive strength vs unit weight.

The compressive strength and unit weight interaction graph of the designed concretes are given in Fig. 3. The unit weights of these hardened concretes range from $1400 \mathrm{~kg} / \mathrm{m}^{3}$ to $1860 \mathrm{~kg} / \mathrm{m}^{3}$. The highest unit weight among the designed concretes was obtained from the concrete series with BP used. While the concrete series in which PP was used constituted the lightest concrete series, it was seen that the weights of the concrete series using FAP were relatively close to those of the BP-series.

The noteworthy result is that concretes with the highest unit weight gave apparently lower strength values, while lighter concrete series gave higher concrete compressive strengths. The best example is the E8, E9 series versus the E1, E2 concrete series in Fig. 3. This conclusion confirms that the concrete series with the higher pozzolanic activity can give higher strength, even though the unit weight of the concrete is low.

\section{Conclusions}

The successful design of SCLWC was carried out using acidic volcanic pumice with different powders. The relatively best result was obtained from the SCLWC, including the river sand and $\mathrm{BP}$, according to the fresh properties. However usage of BP had caused bleeding problem, because of its weak cohesion properties. In the fresh concrete design process, usage of FAP gave better fresh and hardened concrete properties, and was followed by PP containing samples. The best compressive strength and UPV test results were obtained in the series E4, while the worst result was obtained in series E7, without river sand. This study has shown that lighter concrete or concrete having the lower unit weight can give better strength properties. Usage of all these powders in concrete mix can provide sustainable concrete design. This usage leads to eco-friendly concrete design and energy saving.

\section{References}

[1] M. Kurt, Ph.D. Thesis, Atatürk University Graduate School of Natural and Applied Sciences, Erzurum 2009.

[2] G.İ. Sezer, Ş. Yazıcı, A. Sezer, Acta Phys. Pol. A 128, B-37 (2015).

[3] D. Sarıyer, R. Küçer, N. Küçer, Acta Phys. Pol. A 128, B-201 (2015).

[4] S. Özavci, B. Çetin, Acta Phys. Pol. A 130, 316 (2016).

[5] M. Altın, M.T. Çögürcü, M.S. Döndüren, Selçuk Univ. J. Techn.-Online 5, 77 (2006).

[6] M.H. Özkul, Redy-Mix Concrete 125, 61 (2014).

[7] TS EN 206, Concrete - Specification, performance, production and conformity, Turkish Standard Institute, Ankara 2014.

[8] M. Davraz, Ş. Kilinçarslan, H. Ceylan, Acta Phys. Pol. A 128, B-184 (2015).

[9] T. Kotan, M.Sc. Thesis, Atatürk University Graduate School of Natural and Applied Sciences, Erzurum 2009 .

[10] A. Beycioğlu, C. Başyiğit, Acta Phys. Pol. A 128, B-424 (2015).

[11] Z.F. Türkmenoğlu, A.M. Kılıç, T. Depci, Çukurova Univ. J. Faculty Eng. Arc. 30, 105 (2015).

[12] TS 3234, Mining, Placing, Curing, Mix Design and Methods of Testing of Pumice Concrete, Turkish Standard Institute, Ankara 1978.

[13] TSI, Statistic of civil structures, Turkish Statistical Institute, Ankara 2009. 